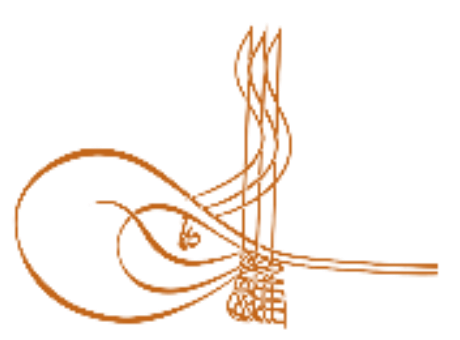

www.turkishstudies.net/turkishstudies
Turkish Studies

eISSN: $1308-2140$

Research Article / Araştırma Makalesi

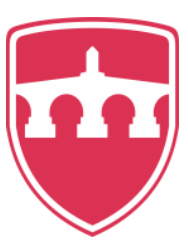

INTERNATIONAL

BALKAN

UNIVERSITY

Sponsored by IBU

\title{
Ortaçağ Sanatında Taçkapı Süslemelerinde Görülen Tetramorf Figürleri Üzerine Birkaç Söz ${ }^{*}$
}

\author{
A Few Words on Tetramorphic Figures Seen in the Ornaments of Portal in Medieval Art
}

\author{
Yunus Berkli**
}

\begin{abstract}
The door, in its singular sense, is the connection element between interior and exterior. It is a formation that is placed inside the wall and has a rectangular form due to its general characteristics. The rectangular form that cuts the architectural structure vertically, while creating the door definition, also has a holistic effect with various complementary form elements. These can be round or pointed arches or they can be created with muqarnas and geometric forms. The crown door in architecture is a stand-alone structure and essentially representative form above normal wall criteria. Decoration and ornamentation elements on Taçkap1 floors refer to an iconographically qualitative repertoire. Tetramorphic animals, animal form and God-Human figure compositions are also encountered in Christian art in a symbolic language. In the crown gate arrangements of Romanesque architecture, mythological figures such as lion, griffon and dragons are reflected in Christian art, but often no explanation can be given about what Asian themes mean. The iconographic forms in the form of animals or plants, which have especially penetrated into the medieval art, are closer to the dictionary of forms that come to the West with Buddhist, Seljuk and pre-art. Oriental motifs were not imbued as purely ornamental elements, the artists of the period showed that they had unlimited imagination in this sense. The formal dictionary of Western art, in particular, is fused with the products offered by the eastern world, elements from the human figure, plant and animal world, are similar to their imaginary or mythological descriptions. The text of the article is to try to explain how the formal features of these elements seen in eastern and western art are compared with their iconographic dimension from a theoretical perspective.
\end{abstract}

Structured Abstract: The door, in its singular sense, is the connection element between interior and exterior. It is a formation that is placed inside the wall and has a rectangular form due to its general characteristics. The rectangular form that cuts the architectural structure vertically, while creating the door definition, also has a holistic effect with various complementary form elements. These can be round or pointed arches or they can be created with muqarnas and geometric forms. The crown door in architecture is a stand-alone structure and essentially representative form above normal wall criteria. Decoration and ornamentation elements on Taçkap1 floors refer to an iconographically qualitative repertoire. Tetramorphic animals, animal form and God-Human figure compositions are also encountered in Christian art in a symbolic language. In the crown gate

\footnotetext{
* Makale metni Hoca Ahmet Yesevi 2. Uluslararası Bilimsel Araştırmalar Kongresi'ne (06-08 Aralık 2019-Erzurum) sunulan bildirinin genişletilmiş halidir.

** Doç. Dr. Atatürk Üniversitesi, Güzel Sanatlar Fakültesi, Temel Eğitim Bölümü

Assoc. Prof. Dr., Atatürk University, Faculty of Fine Arts, Department of Basic Education

ORCID 0000-0003-3650-3681

yberkli@atauni.edu.tr

Cite as/ Atıf: Berkli, Y. (2020). Ortaçağ sanatında taçkapı süslemelerinde görülen tetramorf figürleri üzerine birkaç söz, Turkish Studies, 15(2), 831-840. https://dx.doi.org/10.29228/TurkishStudies.41597

Received/Geliş: 03 February/Şubat 2020

Checked by plagiarism software

Accepted/Kabul: 25 April/Nisan 2020

Published/Yayın: 30 April/Nisan 2020

Copyright (C) MDE, Turkey

CC BY-NC 4.0
} 
arrangements of Romanesque architecture, mythological figures such as lion, griffon and dragons are reflected in Christian art, but often no explanation can be given about what Asian themes mean. The iconographic forms in the form of animals or plants, which have especially penetrated into the medieval art, are closer to the dictionary of forms that come to the West with Buddhist, Seljuk and pre-art. Oriental motifs were not imbued as purely ornamental elements, the artists of the period showed that they had unlimited imagination in this sense. The formal dictionary of Western art, in particular, is fused with the products offered by the eastern world, elements from the human figure, plant and animal world, are similar to their imaginary or mythological descriptions. The text of the article is to try to explain how the formal features of these elements seen in eastern and western art are compared with their iconographic dimension from a theoretical perspective.

In Taçkapı arrangements, a visual space is encountered, in which various depictions are staged together with the abstract geometric shapes that activate the surface of the building beyond its classical form. In the process of the continuation and maintenance of the cultural elements, the application of the origin, hence to the past, to plastic forms. Of course, when plastic forms are evaluated as a result of all stages of art in history, undoubtedly religion takes the first place. It will also be necessary to connect with the religious, political and social structure in which the era of iconographic form is reflected on religious and civil structures or surfaces. In Christian culture, human figures engraved heavily on the portal are represented by religious themes that explain the worldly form. Anthropomorphic representations are also associated with a repetition of pagan beliefs due to antiquity. The iconographic forms and the movement of thought or idea that were not trapped within the boundaries of religion and culture or geography (Bayrakdar, 2013: 217-219) were also effective in shaping and developing art. Entering into animal form is an anionic attitude outside the churches and even $\mathrm{Hz}$. The depiction of Jesus as a lamb is in line with the socio-cultural thought environment of the period. In the first churches established, Hz. The concept of Divinity was not yet imposed on Jesus. The cultural structure that changed as a result of the great influence of the tribes migration was of Origin due to Asia. There are many signs of digestion of this culture in the European geography. It can be easily understood from the works that the Turkish tribes, which were very early, were the most important factors in the spread of the steppe art, namely the Eurasian style, to the North Black Sea and eastern Europe and the examples in European art that these works affect. These effects are strong enough to make themselves felt in almost all of Europe. Information about the effects of Central Asian Turkish art and culture is no longer limited to only artistic activities, it is strong enough to affect daily life, and even in this period, "The Germanic and Slavs are trying to resemble the noble class of European Huns" are included in the statements of various sources (Berkli, 2020: 575-576).

Among the formal elements of medieval Western art, the images representing Tengri in Central Asian art were animal-shaped mythological figures (Adji, 2019: 155-156). The resemblance of the prominent examples in church depiction art attracted the attention of the scientific community and often no clear explanation could be made (Adji, 2019: 102-103). When we look at the examples in Christian art, it is necessary to relate to the medieval period, antopomorphic forms of plastic items processed on the doorways of the crown, a repeat of the pagan beliefs due to antiquity. Attention to similar forms, especially symbolic animal depictions between both cultures, can be explained by the fact that Christian culture is influenced by different religions and cultures, or by common form references.

Keywords: Portal, Iconography, Tetramorph, Representation, Theory

Öz: Kapı, tekil anlamı itibariyle iç ve dış mekan arasındaki bağlantı unsurudur. Duvar içine yerleştirilen ve genel özelliği itibariyle dikdörtgen bir forma haiz beşeri ölçütlere nispet edilen bir oluşumdur. Mimari yapıyı dikine kesen dikdörtgen form, kapı tanımını oluştururken aynı zamanda çeşitli tamamlayıcı biçim elemanlarıyla da bütüncül bir etki gösterir. Bunlar yuvarlak veya sivri kemerler olabileceği gibi mukarnas ve geometrik formlarla da oluşturulabilmektedir. Mimarideki taç kapı, tek başına bir strüktür olarak dikkati çeken ve normal duvar ölçütlerinin üstünde esasen temsili bir formdur. Taçkapı zeminlerinde işlenen tezyinat ve süsleme unsurları ikonografik açıdan nitel bir repertuara göndermede bulunur. Tetramorf hayvanları, hayvan biçimine girme ve Tanrı-İnsan figürü kompozisyonları sembolik bir dille Hıristiyanlık sanatında da tasvirlerine rastlanılmaktadır. Romanesk mimarisinin taçkapı düzenlemelerinde, arslan, grifon ve ejderhalar gibi mitolojik figürler, Hıristiyan sanatına yansımakla beraber, Asyalı temaların ne anlam ifade ettiği konusunda çoğu zaman bir açıklama getirilememektedir. Ortaçağ sanatına özellikle nüfuz etmiş hayvan veya bitki şekilli ikonografik biçimler, Batı'ya Budist, Selçuklu ve öncesi sanatıyla gelen biçim sözlüğüne daha yakındır. Doğulu motifler, 
salt süsleme unsurları olarak uyarlanmamış, dönemin sanatçıları, bu anlamda sınırsız hayal güçleri olduğunu göstermişlerdir. Batı sanatının biçim sözlüğü özellikle doğu dünyasının sunduğu ürünleriyle kaynaştırılmış, insan figürü, bitki ve hayvan aleminden alınmış öğeler, hayali veya mitolojik tasvirleriyle benzerlik gösterir. Makale metni, doğu ve batı sanatında görülen bu öğelerin biçimsel özelliklerinin ikonografik boyutuyla nasıl değerlendirildiğinin karşılaştırılmasını kuramsal bir bakış açısıyla açıklamaya çalışmaktır.

Anahtar Kelimeler: Taçkapı, İkonografi, Tetramorf, Temsil, Kuram

\section{Giriş}

Taçkapı düzenlemelerinde, klasik formunun ötesinde yapı yüzeyini harekete geçiren soyut geometrik biçimlerle birlikte çeşitli tasvirlerin sahnelendiği görsel bir alanla karşılaşılır. Kültürel öğelerin, sanatın devamı ve idame ettirilmesi sürecinde kökene dolayısıyla geçmişe ait plastik formlara müracaatı söz konusu olmuştur. Tabii plastik formların sanatın tarihi içerisinde geçirdiği aşamaların bir bütünü neticesinde değerlendirildiğinde hiç kuşkusuz din ilk sırada yer alır. İkonografik biçim dağarcığının dini ve sivil yapılara veya yüzeylere aksettirilmesi aşamasında dönemin bulunduğu dini, siyasi ve sosyal yapısıyla da bağlantı kurmak gerekecektir. Hıristiyan kültüründe, taçkapı yüzeyinde ağırlıkla işlenen insan figürleri dünyevi biçimi açıklayan dinsel temalarla temsil edilir. Antropomorfik temsiller de antik çağ dolayısıyla pagan inancının bir tekrarıyla ilişkilendirilir. İkonografik biçimler, dinin ve kültürün veya coğrafyanın kendi sınırları içerisinde hapsolmamış bilakis düşünce veya fikir hareketleri de (Bayrakdar, 2013: 217-219) sanatın şekillenmesinde ve gelişmesinde etkili olmuştur. Hayvan biçimine girme anikonik bir tavırla kiliselerin dışında resmedilmesi hatta Hz. İsa'nın kuzu şeklinde tasvir edilmesi yaşanan dönemin sosyo-kültürel düşünce ortamıyla paralellik içerir. Kurulan ilk kiliselerde Hz. İsa'ya Tanrısallık kavramı henüz yüklenilmemişti. Kavimler göçünün büyük etkisi sonucu değişen kültür yapısı Asya dolayısıyla Bozkır kökenliydi. Bu kültürün Avrupa coğrafyasında hazmedilmesinin birçok belirtisi görülmektedir. Oldukça erken devirlerden olmak üzere Türk boylarının Kuzey Karadeniz ve doğu Avrupa'ya bozkır sanatının yani Avrasya üslubunun yayılmasında en önemli etken oldukları bıraktıkları eserler ve bu eserlerin etki ettiği Avrupa sanatındaki örneklerinden, rahatlıkla anlaşılmaktadır. Bu etkiler, Avrupa'nın hemen tamamında kendisini hissettirecek kadar güçlüdür. Artık Orta Asya Türk sanatı ve kültürüne ait etkilerin sadece sanatsal faaliyetlerle sınırlı kalmadığı, günlük hayata da tesir edecek kadar güçlü olduğu hatta bu dönemde "Cermen ve Slavların Avrupa Hunlarının asil sınıfına benzemeye çalıştıkları" hakkındaki bilgiler çeşitli kaynakların ifadelerinde de yer almaktadır (Berkli, 2020: 575-576).

Ortaçağ Batı sanatının biçimsel öğeleri arasında Orta Asya sanatında, Tengri’yi temsil eden imgeler, hayvan biçimli mitolojik figürlerdi (Adji, 2019: 155-156). Kilise tasvir sanatında öne çıan örneklerin benzerlik göstermesi bilim camiasının ilgisini çekmiş ve çoğu zaman net bir açıklama getirilememiştir (Adji, 2019: 102-103). Hıristiyan sanatındaki örneklerine baktı̆̆ımızda, Ortaçağ dönemi, taçkapı zeminlerinde işlenen plastik öğelerin antropomorfik formları, antik çağ dolayısıyla pagan inancının bir tekrarıyla bağlantı kurmak gerekir. Her iki kültür arasında benzer biçimlere, özellikle sembolik hayvan tasvirlerine dikkat çekilmesi Hiristiyan kültürünün farklı din ve kültürlerin etkisinde olması veya ortak biçim referanslarıyla açıklanabilir.

\section{Taç Kapıya İkonografik Bir Temsil Bağlamında Kuramsal Yaklaşım}

Kapı tekil bir yapı elemanı olmasının dışında birçok özelliği içinde barındıran, insanı Tanrı'ya sevk eden kozmolojik bağlantıdır. Bu yönüyle İlahi güce açılan ve ona nispet edilen aralık, metafiziksel olarak sınırlı dünyanın aşılmasın ifade eder. Türklerde, mimari yapıda taçkapı ile ilgili örneklerin erken dönemde, Orta Asya ve Pers bölgelerinde uygulandığına dair bilgiler mevcuttur (Çaycı, 2017: 129). İslami dönemle birlikte dini yapılarda taçkapıdan sonra iç mekan prototipini yansitan bir başka yapı unsuru ise mihraplar olmuştur. Uhrevi boyutu itibariyle hakikate yönelimin biçimsel göstergeleri, İslam felsefesinde derin anlamlar kazanmıştır. Mimari yapıda kozmosu ifade 
eden taçkapı ve benzeri formlar olarak nitelendirilen mihrap ve mezar taşlarında da biçimsellik almıştır (Çaycı, 2017: 152). Fiziksel olarak bulundukları yapılarda dışa taşma ve ortak form özelliği gösterirler. Somut görünümlerinin dışında maneviyata sevk edebilecek öte dünyayı temsil eden yarı açık kozmos alanlar meydana gelmiştir. Hıristiyan kültüründe kapı, bizzat Hz. İsa ile özdeşleştirilir. Ortaçağ taçkapılarının dini açıdan manevi anlamı göğün kapıları yani gündönümü kapıları bir başka ifadeyle döngüsel aralıklardır (Burckhardt, 2017, 104). Kilise kapısı ikonografik açıdan mimari sanatılla doğrudan ilişkili olması kozmoloji, imgelerin dini konuları yansıtması teoloji, mistik boyutu ise metafizik yoluyla tezahürünü ortaya koymaktadır (Hafiz, 2015: 282). Dolayısıyla kozmolojik plan üzerinde, dinsel temaların zemine uyarlanması, modellerin kökenine gönderme yapmaktadır. Evreni aynı zamanda kutsal mekanı temsil eden mimari plan, dinin uhrevi ve mistik karakterini yansıtmaktadır. Hıristiyan tapınağında bu, Logos'un insanın forma dönüşmüş halidir. Kozmik döngüye yapılan gönderme, ilahi planı yansıtan yapı aracılı̆̆ıyla tezahür ettirilir. İkonografik temsiller, mitolojik karakterin en önemli göstergesidirler (fotoğraf 1). Huristiyan sanatının biçimsel öğeleri arasında özellikle ortaçağ döneminde sıkça rastlanılan hayvan ve bitki tasvirleri, dünya veya evren yapısında duyulan kozmogonik özdeşleştirmelerin bir dışavurumunu ortaya koymaktadır (Gültepe, 2019: 1495).

Sembolik bir dilin sonucu, reel alem görünenin ötesinde madde ve cisimden arındırılmış mitolojik varlıklar ile insan ya da Tanrı arasında bir bağ kurulmaya çalışılmıştır. Antik Yunan ve Roma sanatından itibaren izlenebilen Tanrı-İnsan anlayışı, plastik formlarını çok defa tekrarlayabilmiştir. Ortaçağa gelindiğinde eski pagan inancın izleri Hıristiyan dini içerisinde merkezi bir figür aynı zamanda çeşitli simgelerle bütünleştirilmiştir (fotoğraf 3, 4). İsa tasvirleri, kutsal temaların simgesel boyutu ve romanesk sanatından sık sık yer alan dört hayvan (tetramorf) arasında görülmektedir (Bazin, 2015: 91). 1120 tarihli Moissac Manastırının kilisesi ana kapı alınlığı dört varlığın birleşiminden meydana gelen sembolik bir kompozisyon örneğini yansıtmaktadır (fotoğraf 4). Taçkapıda Mesih'in kıyamet günündeki hali resmedilmiştir. Tetramorf hayvanları ve vahiy kitabının yirmi dört yaşlısı ile birlikte Tanrı-İnsan figürü sembolik bir dille Hıristiyanlık öncesi bir kökene sahiptir (Burckhardt, 2017: 120). Romanesk mimarisinin taçkapı düzenlemelerinde, arslan, grifon ve ejderhalar gibi mitolojik figürler, Hıristiyan sanatına yansımakla beraber, Asyalı temaların ne anlam ifade ettiği konusunda çoğu zaman bir açıklama getirilememektedir (Burckhardt, 2017: 120). Ortaçağ sanatına özellikle nüfuz etmiş hayvan veya bitki şekilli ikonografik biçimler, Batı'ya Budist, Selçuklu ve öncesi sanatıyla gelen biçim sözlügüne daha yakındır. Doğulu motifler, salt süsleme unsurları olarak uyarlanmamış, dönemin sanatçıları, bu anlamda sınırsız hayal güçleri olduğunu göstermişlerdir. İnsan figürünü, bitki ve hayvan dünyasından alınmış öğeler, hayali ya da mitolojik tasvirleri konusunda doğu dünyasının sunduğu ürünleriyle kaynaştırabilmişlerdir (Bazin, 2015: 91). Kanatlı meleklerin, arslan, boğa ve kartal figürlerin göklerin hakimi olan Tengri'yi canlandıran dolaylı temsilleriydi (Adji, 2019: 155). Tekrar eden insan figürselliğini aşma çabası, birbirini destekleyen ve kaynaşan formlar, farklı kültürlerden alınan parçalarla bir araya getirilmiş izlenimi vermektedir. Roma, antik Yunan sanatından yararlanmış, Bizans Roma ve doğudan kaynaklanmış, Romanesk sanatı ise Bizans, Orta Asya ve antikçağın bir melez ürünü olarak canlandırılmaya çalışılmıştır (Bazin, 2015: 91). Batı sanatında görülen melez biçim formülasyonu, sanat yapıtının biçimsel dağarcı̆̆ını özle olan bağlantısında, geleneğe ait net bir üslubu ortaya koyamadığı anlaşılmaktadır. Kültürün vermeye çalıştığı inanç sistemi, görünümlerini farklı sanat formlarıyla açığa çıkarmıştır. Sembol ile kutsal karakterin bir arada sunulması, üslup ile imgenin dini içeriğiyle ifade edilmiş olmasını açıklamaktadır.

Doğu sanatında Tanrı, insan veya tabiat arasında kurulmaya çalışılan özdeşleştirme durumu, batı sanatının nesnel dünyasını yansıtan aklın rasyonalitesiyle değil, sembollerin mistik biçim anlayışıyla tezahür ettirilmeye çalışılmıştır. Bir başka ifadeyle biçim ve öz birlikteliği, aynı kökene tanıklık etmesi halinde geçerliliğini koruyabilmektedir. Kiliselerde tasvir edilen tetramorf biçimlerin evangelistlerin yani İnciller hakkında vaaz edenlerin dolaylı temsilleri ve Hezekiel'in (Zülkif peygamber) gördügü vizyondan alınmış sembollerde olabileceği hakkında yorumlar bulunmaktadır 
(Jung, 2017: 16). Hıristiyan kültürü, dini gereği merkezi bir figür anlayışılla doğrudan verilmeye çalışılan antropomorfik bir tanrı formunu benimser. Bunun yanı sıra kültürün hayvan ve bitki biçimlerini de temel alan karmaşık anikonik motiflere de yer verdiği görülür (Eco, 2017: 702) (fotoğraf $1,5,6,7,9$ ). Huristiyanlığın erken dönemlerinde romanesk sanatının metamorfoz ve dinamizm anlayışı, Moissac manastırının kilisesindeki kemer alınlığındaki İsa tasviriyle de paralellik içermektedir (fotoğraf 4). İmge ve yeni tema arayışı ile batı ortaçağı, klasik ilkçağa ait eski felsefi tartışmayı da üstlenmiştir (Durand, 2017: 35). Asya sanatına ait motifler arasında güneş hayvanları olarak bilinen aslan ve kartal figür kombinasyonları, Mesih'in tanrı ve insan olmak üzere ikili tabiatını simgeleyen tasvirler, anikonik bir tavırla kiliselerin dışında gösterilmeye dönük isteksizliğin var olduğunu betimleyen işaretleri olmuştur (Burckhardt, 2017: 114-115). Hıristiyan kültüründe bu tür biçimlere ihtiyaç duyulması, dönem dönem patlak veren ikonakırıcılık anlayışı, eski Ahit’te tanrısal olanı resmetme yasağına dair dönüşün hala yaşatılmaya çalışıldığını açıklamaktadır. İkonakırıcılığın VIII.-IX. Yüzyıllarda siyasal, toplumsal ve teolojik açıdan birçok nedeni vardı. Hıristiyanların ilk iki yüzyılı, On Emirde bildirilen yasağa uymaları, Tanrı'nın temsili tartışmasını da beraberinde getirmişti (Eliade, 2017: 80). Adji'ye göre; "Hıristiyanların kitabı İncil, IV. Yüzyılın sonuna doğru ortaya çıkmıştır. 691 yılında metni tamamlanmış olan Yeni Ahit'in bir parçası olmuştur. Hıristiyanlar bu tarihten itibaren, Trullo Konsili'nden sonra İsa'yı ikonaların üzerine insan suretinde resmetmeye başladılar. Bunun öncesinde ise Türkçe sözlerle Tanrı sembolüne dua ediyor, İsa'yı kuzu suretlerinde yani koyunlarda tasvir ediyorlardı" (Adji, 2019: 112). IV. Yüzyıl başlarında, batı kültürünü ve toplum yapısını değişime uğratan kavimler göçü ile ibadet dili dahil Altay menşeli olduğu kaynaklarda yer almaktadır (Berkli, 2011: 69-70, Strzygowski, 1975: 107).

IV. Yüzyılda batı ve doğu kiliseleri arasında bazı farkların olduğu ifade edilmektedir. Eliade, "Kilise içinin dört bölümü dört ana yönü simgeler. Kilisenin içi evrendir. Sunak, doğuda bulunan cennettir. Tapınağın kral kapısına "cennetin kapısı" denilirdi. İsa Mesih mezarından kalktı ve bize cennetin kapılarını açtı. Batıda bu tam tersi düşünülmüş, kıyamet gününü ve bedenlerin dirilmesini bekleyen ölülerin ebedi istirahatgâhlarının, büyük acı ve ölüm karanlıklarının bölgesidir" şeklinde bir açılama getirmektedir (Eliade, 2017: 76-77).

Ahmed Musa'nın Miracname isimli çalı̧̧masında, Hıristiyan sanatında örneklerini verdiğimiz hayvan karakterli insan figürlerine rastlamaktayız. Muhammed ve Dört Başlı Melek figürün betimlendiği kompozisyon, içerik bakımından klasik İslam tasvir üslubun ötesinde Orta Asya etkileri taşımaktadır (Çağman, 1989: 108-109). XIV. Yüzyıl İlhanlı döneminde faaliyet gösteren Musa hakkında, minyatürlerinde "Resmin yüzünden peçeyi indirdi ve o devirde moda olan resmi icad etti" denmesi bir figür ressamı olarak islam dinin kullanmadığı bir suret formunu ortaya koymaktadır (İnal, 1995: 88, İpşiroğlu, ve Eyüboğlu, 1955: 102) (fotoğraf 2). Kompozisyonda yer alan dört başlı figür, aslan, boğa, kartal ve insan başından oluşur. Tasvirin simgesel biçim anlayış1 eski Türklerde mitolojik bir düşünce yapısı dolayısıyla tabiatla iç içe geçen bir yaşam tarzının uygulamaya geçirildiği bir üslubun izlenimlerini vermektedir. Merkezi bir tanrı formunun ötesinde tanrıya ulaştıracak hayvan, bitki ve geometrik biçimlerin dolaylı temsillerine müracaatı söz konusu olmuştu (Gültepe, 2016: 181-197).

\section{Sonuç}

İkonografik bir temsil özelliği gösteren taçkapı, mimari yapı elemanı dışında, zemini üzerinde işlenen plastik öğelerin anlamsal içerikleriyle niteliksel bağlam oluşturduğu dolayısıyla bu ve öte dünya arasında bir geçiş olma unsuru ile işlevsel bir yapıya sahiptir diyebiliriz. Bu anlamda farklı anlam dağarcıklarının ortaya çıkması veya anlamlandırılması kültürlerin din ve inançlarından kaynaklanmaktadır. Batı sanatında Taçkapı zeminlerinde örneklerini verdiğimiz plastik öğeler içerisinde ortak görülen bazı biçimlere dikkat çekilmesi, hayvan biçimine girme simgesel bir sanat diliyle yansıtılmıştır. Hıristiyan kültürünün plastik biçimleri genellikle antropomorfik olması, antik çağ dolayısıyla pagan inancının bir tekrarıyla bağlantı kurmak gerekir. Tanrının insan biçiminde tasavvuru, bu kültürün içerisinde dönem dönem ortaya çıkan tasvir yasağı, dinin hala zemin 
bulamamış farklı dinlerin ve kültürlerin etkisinde olmasıyla açıklanabilir. Doğu sanatında ise tam tersi bir form anlayışıyla karşılaşı1ır. Tanrı, insan veya tabiat arasında kurulmaya çalışılan özdeşleştirme durumu, batı sanatının nesnel dünyasını yansıtan aklın rasyonalitesiyle değil, sembollerin mistik biçim anlayışıyla tezahür ettirilmeye çalışılmıştır. Bir başka ifadeyle biçim ve öz birlikteliği, aynı kökene tanıklık etmesi halinde geçerliliğini koruyabilmektedir.

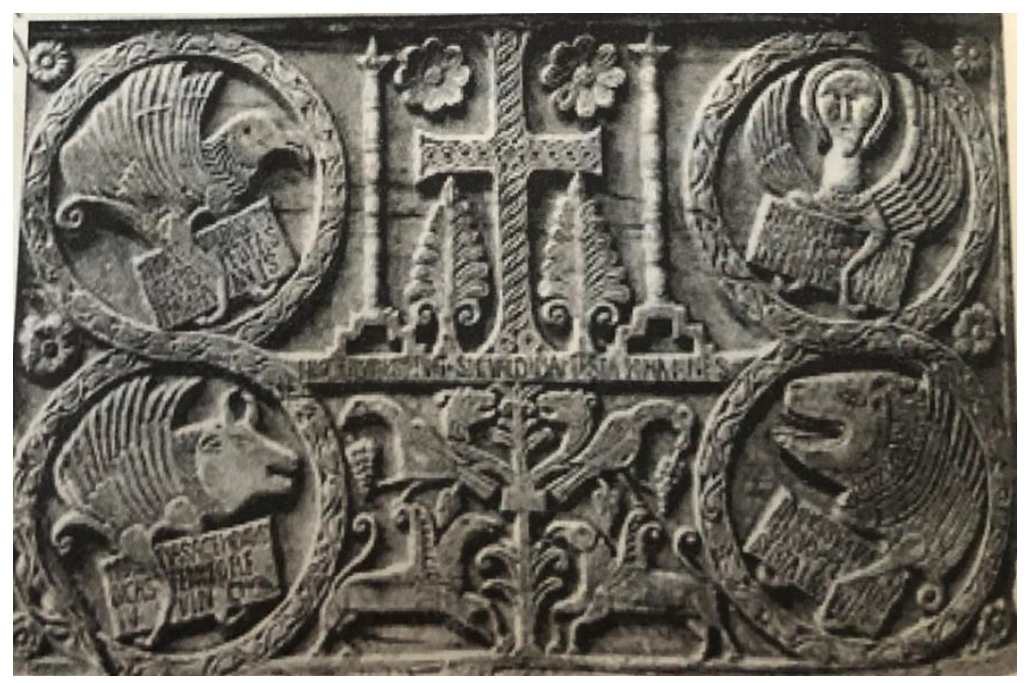

Fotoğraf 1. Dört İncil Yazarlarının Simgeleri, Oyma Mihrap Alınlığı, 8. Yüzyıl Sonları, Cividale (Germain Bazin)

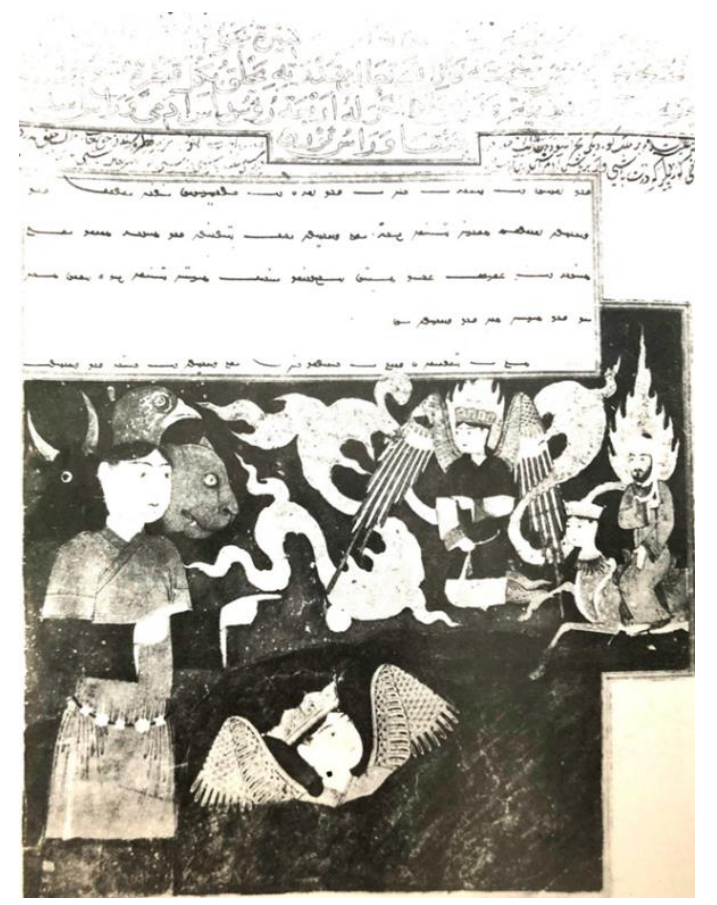

Fotoğraf 2. Muhammed ve Dört Başlı Melek, Miracname, Paris Bibl. Nat., Suppl. Turc. 190, 32v (I. Stchoukine) ${ }^{1}$.

\footnotetext{
${ }^{1}$ Güner İnal, Türk Minyatür Sanatı (Başlangıcından Osmanlılara Kadar), Atatürk Kültür Merkezi, Ankara 1995, R. 60.
} 


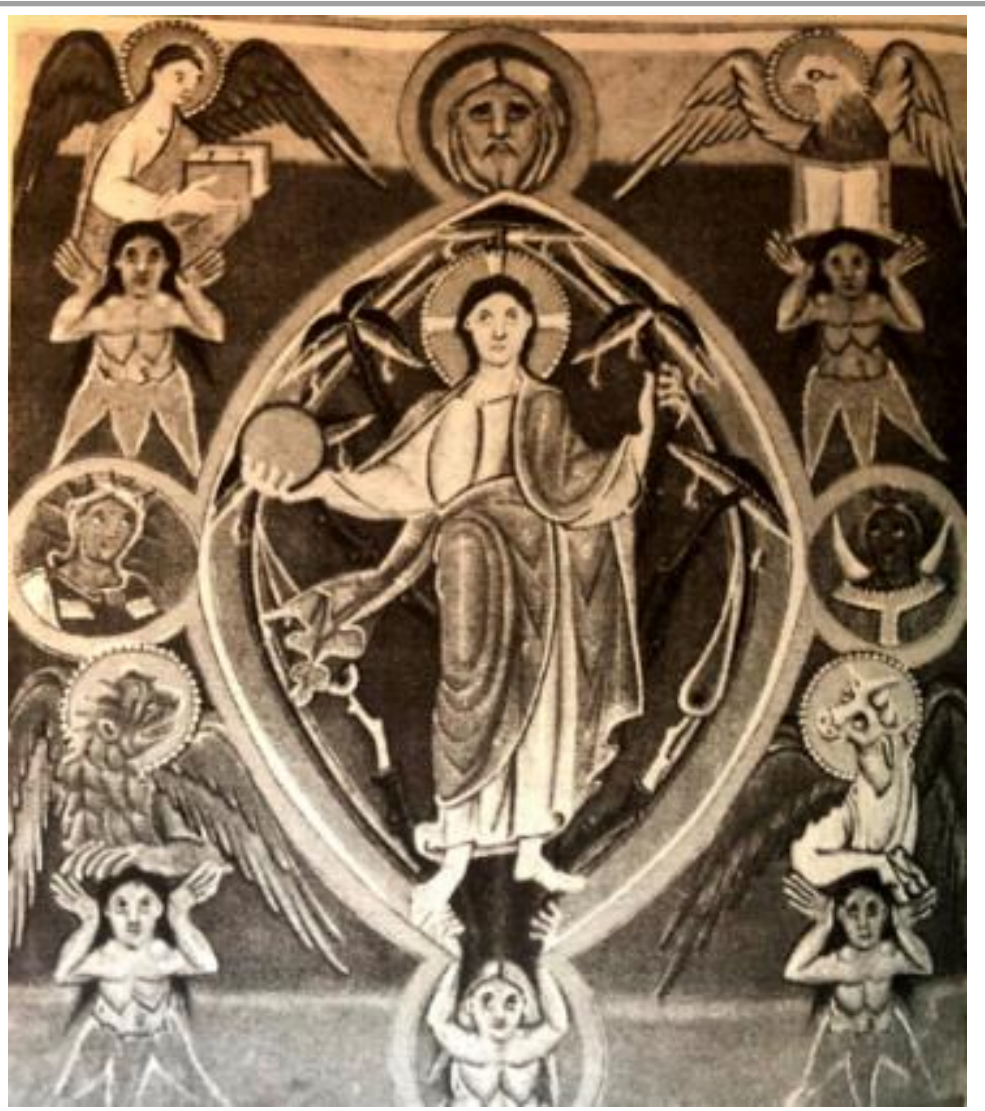

Fotoğraf 3. Kurtarıcı İsa, Bamberg Katedrali’ndeki Apokalips (kıyamet gününe dair alametler), Münih (Bazin)

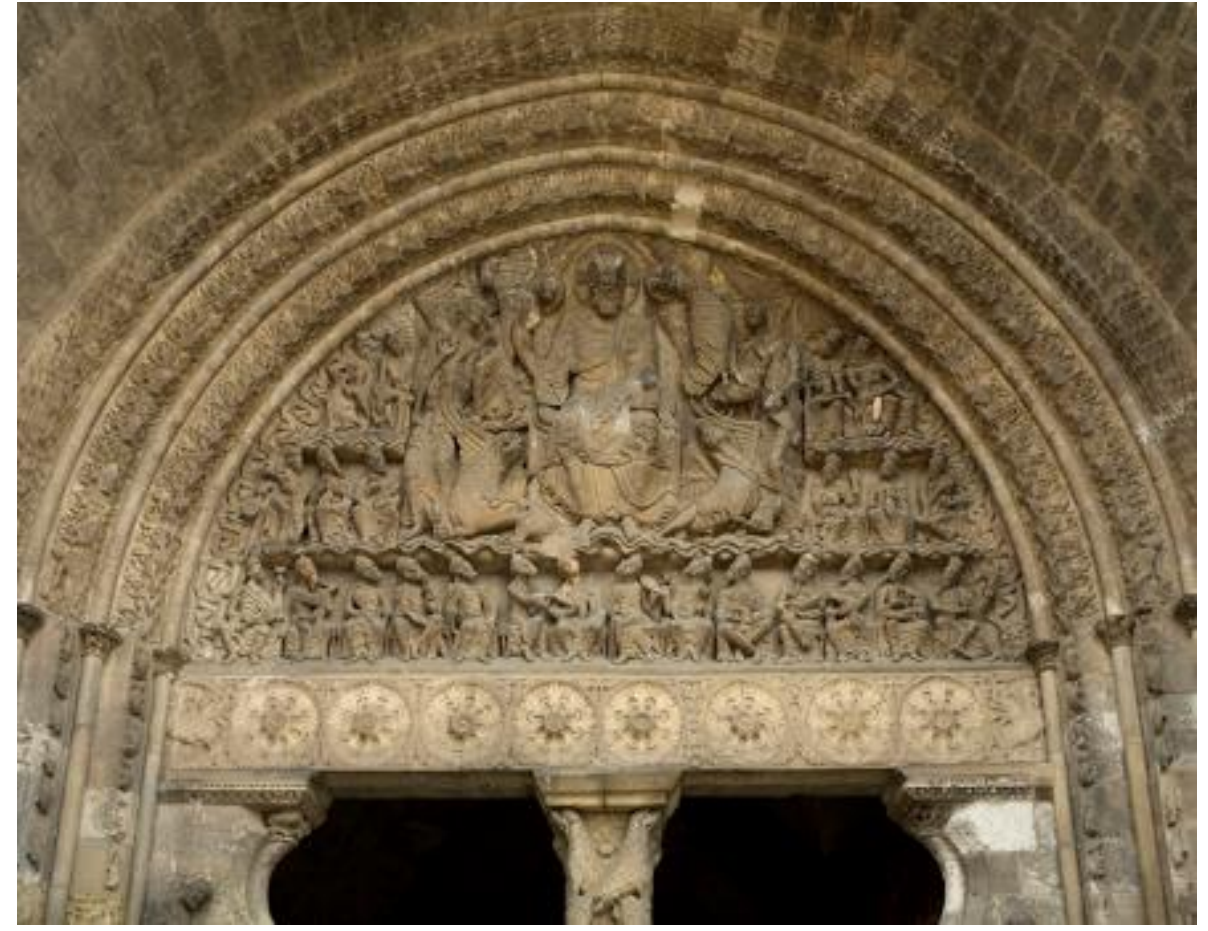

Fotoğraf 4. Moissac Manastır Kilisesi, Taçkap1 ${ }^{2}$

2 https://upload.wikimedia.org/wikipedia/commons/4/46/Moissac\%2C_Abbaye_Saint-Pierre-PM_15080.jpg

(Erişim Tarihi: 08.08.2019). 

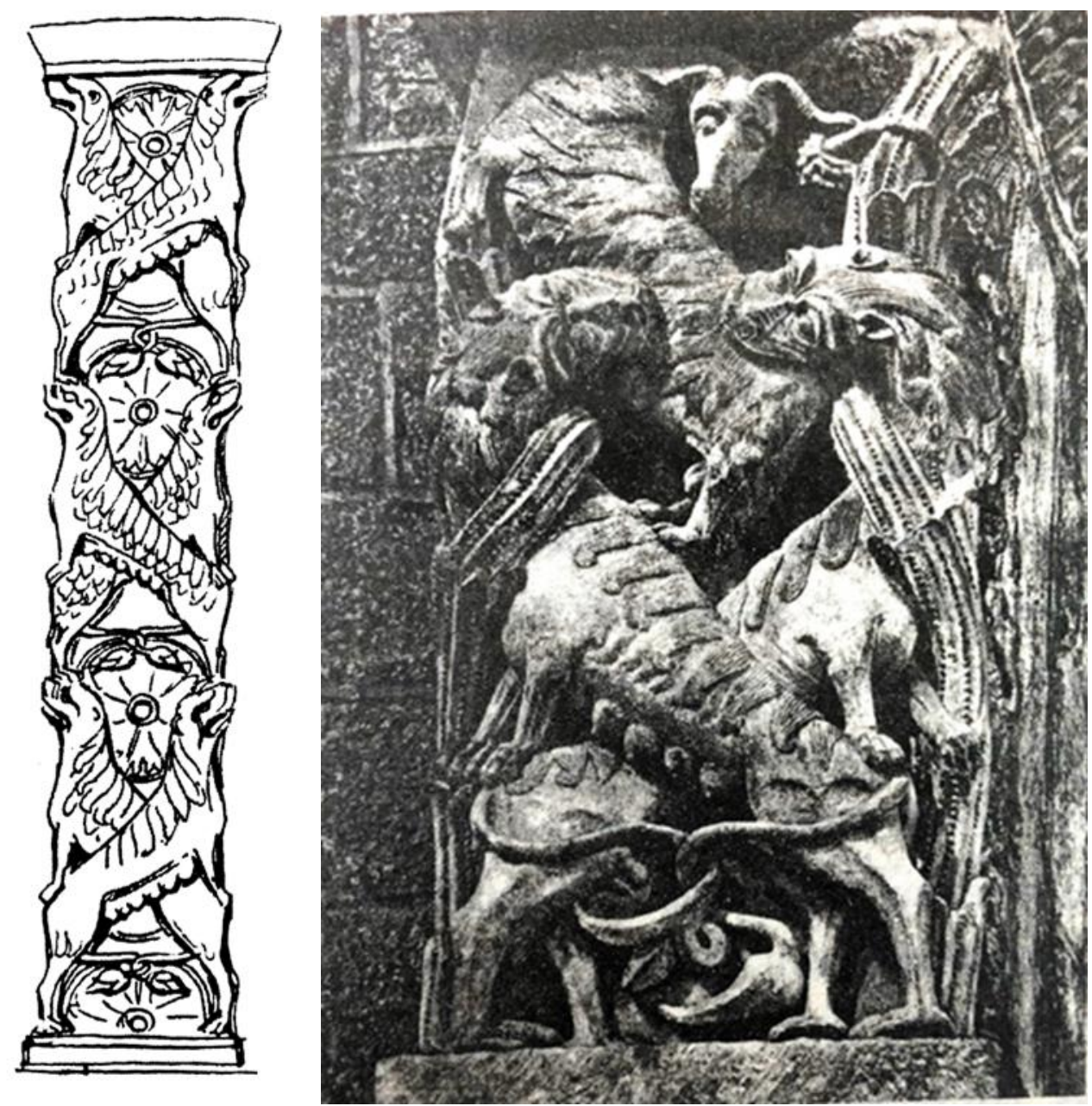

Fotoğraf 5. Moissac Manastırı'dan Fotoğraf 6. Sainte Marie'deki Kabartmalı Sütun, Souillac, 12. Yüzy1l (Bazin) Merkezi Kemer Ayağı (Titus Burckhardt)

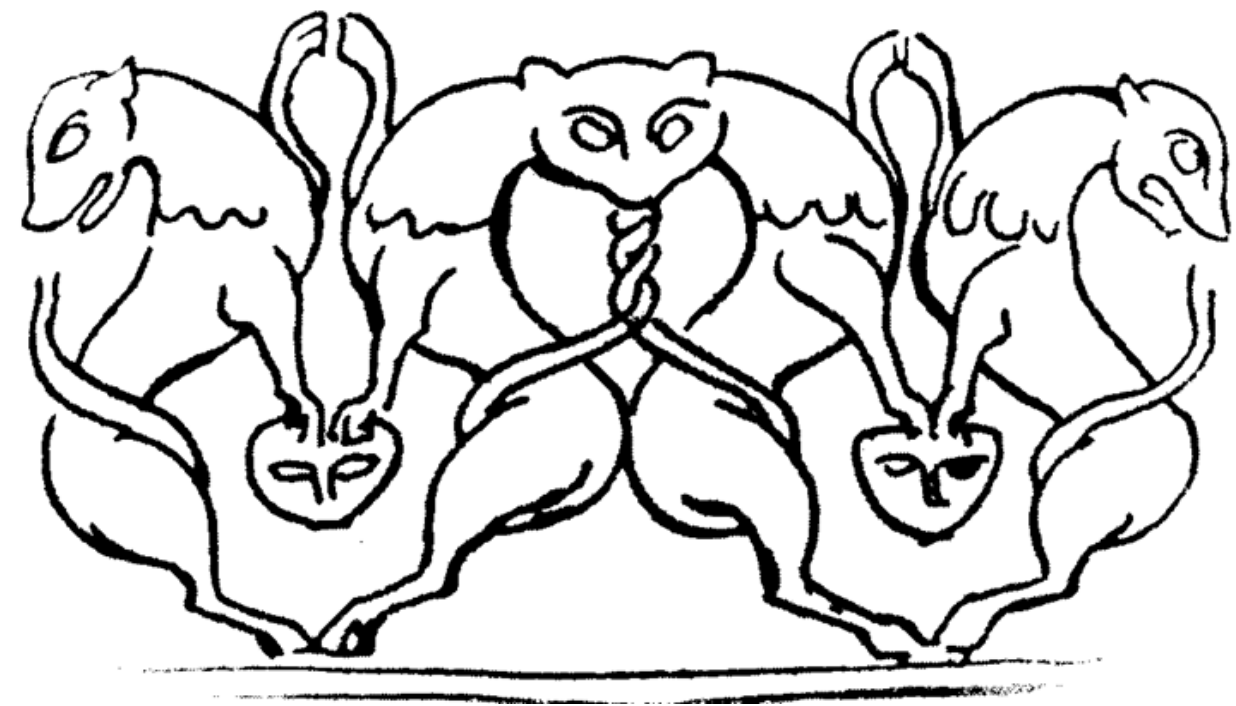

Fotoğraf 7. Basel Katedrali’nin Romanesk Taçkapısındaki Çift Aslan Şekli (Titus Burckhardt) 


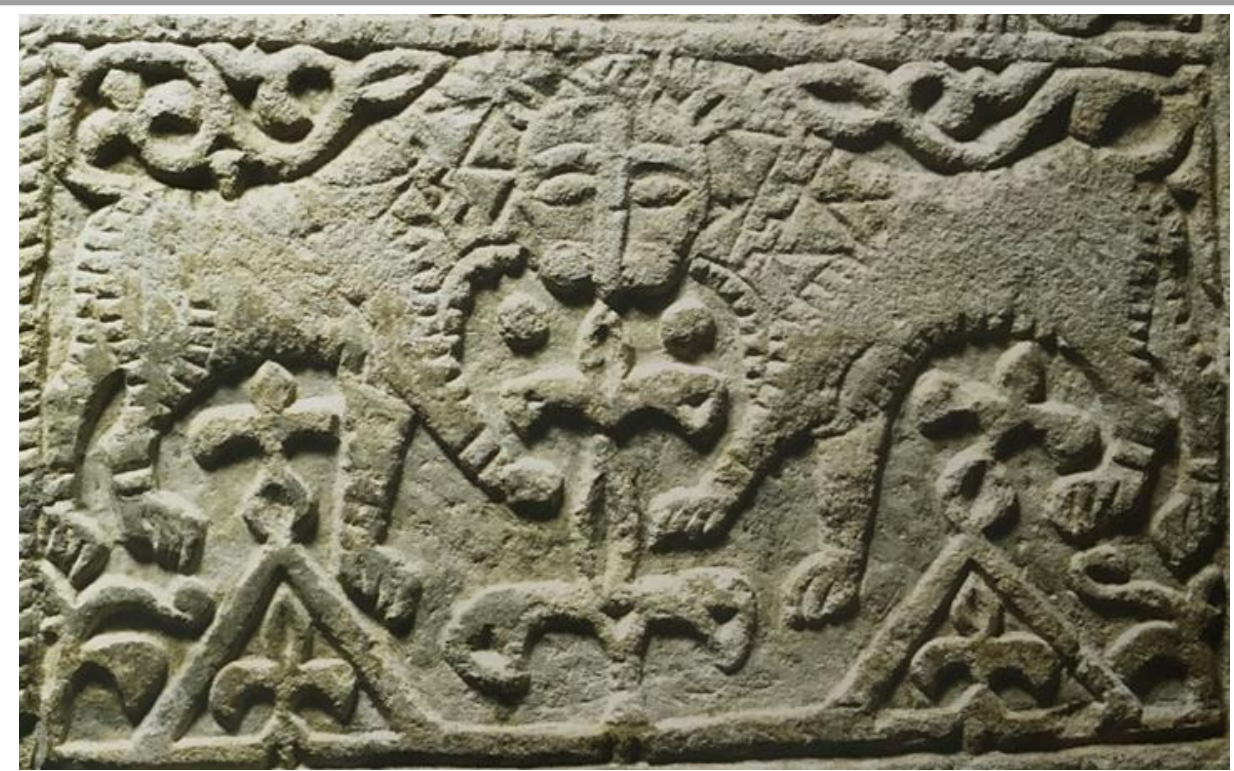

Fotoğraf 8. 12. Yüzyıl Büyük Selçuklu Dönemine Ait Bir Pano Üzerinde Çift Aslan Şekli
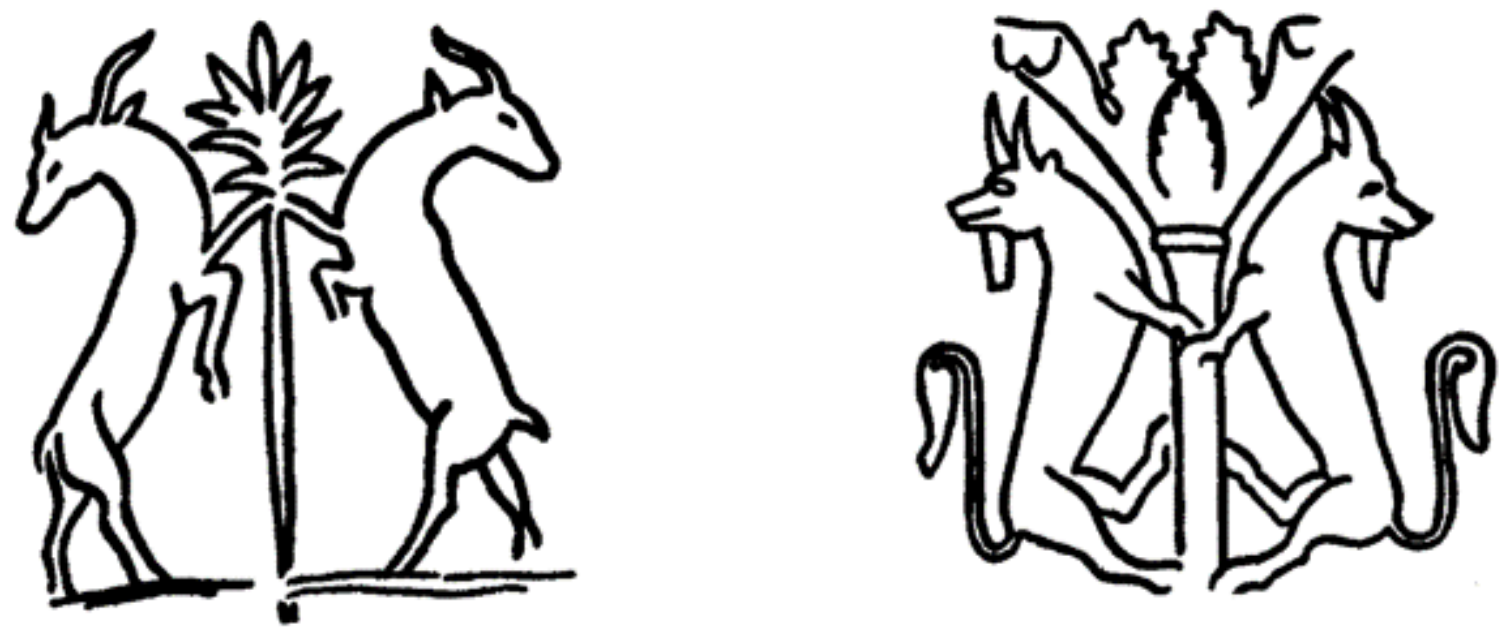

Fotoğraf 9. Bir Asur Silindir Mührü ile Saint-Martin -d'Ainay’ın Bir Sütun Başlığındaki Ayrıntının Karşılaştırılması (Bazin)

\section{Kaynakça}

Adji, M. (2019). Türklerin Saklı Tarihi. Çev. Varol Tümer, Kaynak Yayınları, İstanbul.

Bayrakdar, M. (2013). Yunanistan'da Saka Türk'ü Üç Filozof. Akçağ, Ankara.

Bazin, G. (2015). Sanat Tarihi Sanatın Illk Örneklerinden Günümüze. Çev. Selahattin Hilav, Kabalc1 Yayınc1lk, İstanbul.

${ }^{3}$ Büyük Selçuklu Mirası Müzeler, I. Cilt, Kristal Matbaa, İstanbul 2013, s. 258. 
Berkli, Y. (2020). “Avrupa Sanatının Temellerinde Orta Asya Türk Sanatının İzleri”. Sosyal Bilimler Ekev Akademi Dergisi, Say1 81, ss. 571-586, Erzurum.

Berkli, Y. (2011). Türk Sanatında Avrasya Üslubunun Evreleri (Avrupa ve İslam Sanatına Etkileri). Atatürk Ünv. Yayınları. Erzurum.

Burckhardt, T. (2017). Doğuda ve Batıda Kutsal Sanat Sanatın Illkeleri ve Yöntemleri. Çev. Tahir Uluç, İnsan Yayınlan, İstanbul.

Çağman, F. (1989). "Ahmed Musa”, TDV İslâm Ansiklopedisi 2. Cild, 108-109, https://islamansiklopedisi.org.tr/ahmed-musa (Erişim Tarihi: 10.09.2019).

Çaycı, A. (2017). İslam Mimarisinde Anlam ve Sembol. Palet Yayınları, Konya.

Durand, G. (2017). Sembolik İmgelem. Çev. Ayşe Meral, İnsan Yayınları, İstanbul.

Eco, U. (2017). Ortaçă̆ Katedraller Şovalyeler Şehirler. Çev. Leyla Tonguç Basmacı, Alfa İstanbul.

Eliade, M. (2017). Dinsel İnançlar ve Düşünceler Tarihi 3, Muhammed'den Reform Çağına, Çev. Ali Berktay, Alfa, İstanbul.

Gültepe, G. (2019). "Subjeden Objeye Görsel Plastik Bağlamında Mitolojik Tahayyül”. Turkish Studies Social Sciences, Volume 14 Issue 4. pp. 1489-1498, Ankara.

Gültepe, G. (2016). Plastik Sanatlarda Soyut Somut Gösterge ve Görseller Üzerine Metaforik Bir Yaklaşım. Sanatta Yeterlik Tezi. Atatürk Üniversitesi Sosyal Bilimler Enstitüsü, Erzurum.

Hafiz, M. (2015). Kutsal ve Sanat. Dört Mevsim Kitap, İstanbul.

İnal, G. (1995).Türk Minyatür Sanatı (Başlangıcından Osmanlılara Kadar). Atatürk Kültür Merkezi, Ankara.

İpşiroğlu, M. S., Eyüboğlu, S. (1955). Fatih Albümüne Bir Bakış, İstanbul Üniversitesi Edebiyat Fakültesi Yayınları, İstanbul.

Jung, C. G. (2017). Insan ve Sembolleri. Çev. Hatice Mukaddes İlgün, Kabalcı Yayıncıllk. İstanbul.

Strzygowski-J., Glück-H. ve Köprülü Fuad (1975). Eski Türk Sanatı ve Avrupa’ya Etkisi. Çev. A. Cemal Köprülü, İş Bankası Yayınları, Ankara. 